\section{El Bureau des Longitudes y la fundación del Observatorio de La Plata en la Argentina (1882-1890)}

\section{The Bureau of Longitudes and the founding of the La Plata Observatory in Argentina (1882-1890)}

\section{Marina Rieznik}

Professora da Facultad de Ciencias Sociales e da Facultad de Filosofía y Letras/ Universidad de Buenos Aires; pesquisadora visitante no Instituto Iberoamericano de Berlín; bolsista do Conicet; pesquisadora do Instituto de Investigaciones Científicas y Técnicas/ Universidad Nacional de Quilmes.

marinarieznik@hotmail.com Venezuela 3921, 2b

1211 - Ciudad Autónoma de Buenos Aires - Argentina

Recebido para publicação em junho de 2009. Aprovado para publicação em fevereiro de 2010.
RIEZNIK, Marina. El Bureau des Longitudes y la fundación del Observatorio de La Plata en la Argentina (1882-1890). História, Ciências, Saúde - Manguinhos. Rio de Janeiro, v.17, n.3, jul.-set. 2010, p.679-703.

\section{Resumen}

En 1882, el director del Observatorio de Córdoba, Argentina, se involucró en un debate sobre misiones internacionales que observaban el pasaje de Venus por delante del Sol, criticándolas por causar un "perjuicio a la ciencia, dejando la sustancia en busca de una sombra". El gobernador de la provincia de Buenos Aires y miembros del Bureau des Longitudes de Francia impulsaban las misiones; los instrumentos utilizados servirían para la fundación de otro observatorio local en La Plata. El segundo director del observatorio cordobés diría que los trabajos realizados en La Plata tenían tanta utilidad como "un solo pozo de balde en la irrigación de la zona recorrida por los canales de Córdoba". Se mostrará la competencia entre redes de trabajo internacionales oculta detrás de estas acusaciones y las consecuentes disputas interinstitucionales.

Palabras clave: historia; astronomía; Bureau des Longitudes; La Plata; Argentina.

\section{Abstract}

In 1882, the director of the Córdoba Observatory becameinvolved in a debate over international missions that were observing the transit of Venus across the sun, criticizing them for doing "harm to science, leaving substance aside in search of a shadow." The governor of Buenos Aires province and members of France's Bureau of Longitudes fostered these missions, and the instruments they used would serve in the founding of the local observatory in La Plata. The Córdoba observatory's second director would later statethat the work carried out in La Plata had been as useful as "a single well bucket in irrigating the area covered by Córdoba's canals." The article reveals the hidden rival ry between international networks engaged in mutual accusations and the ensuing disputes between institutions.

Keywords: history; astronomy; Bureau of Longitudes; La Plata; Argentina. 
$\mathrm{D}$ esde 1871 en Córdoba, Argentina, en un observatorio astronómico financiado con fondos estatales, un equipo de astrónomos norteamericanos construía la parte austral de los mapas y catálogos celestes iniciados por colegas suyos en el hemisferio norte. Los dirigía Benjamín Gould, astrónomo norteamericano entrenado entre científicos germanos dirigidos por el astrónomo Friedrich Argelander, director del observatorio de la Universidad de Göttingen. ${ }^{1}$

En 1882 Gould, involucrado en un debate respecto de misiones internacionales que estaban observando el pasaje de Venus por delante del disco solar, dijo que realizar observaciones que pretendían medir la distancia Tierra-Sol que, según él, no habían tenido demasiada eficacia en el pasado, era causar un "perjuicio a la ciencia, dejando la sustancia en busca de una sombra" (Gould, nov.1882). En tanto, en la provincia de Buenos Aires, miembros del Bureau des Longitudes de Francia impulsaban las misiones y el gobernador dictaba un decreto provincial que les destinaba fondos, alegando que los instrumentos utilizados servirían para la fundación de otro observatorio en la ciudad de La Plata. ${ }^{2}$

A fines del mismo año se decretó la partida presupuestaria para la construcción de la institución y el gobernador de la provincia nombró como director del observatorio a uno de los promotores de las misiones para el pasaje de Venus, Francis Beuf, ex oficial de la Marina francesa que había integrado la primera generación de militares formados entre los miembros del Bureau. Las tareas en el observatorio platense se pusieron en marcha en 1885. Al año siguiente, John Thome, segundo director del observatorio cordobés, diría que los trabajos astronómicos impulsados en la institución platense por la dirección del Observatorio de París y del Bureau tenían tanta utilidad como la de "un solo pozo de balde en la irrigación de la zona recorrida por los canales de Córdoba" (Thome, sept. 1886).

Estas y otras opiniones de los sucesivos directores cordobeses sobre el trabajo realizado en el observatorio platense han sido leídas acríticamente por la historiografía, tiñendo las interpretaciones sobrelas fuentes encontradas. En distintas ocasiones, JoséBabini, por ejemplo, no titubeó en decir que las publicaciones del observatorio platense reflejaban en realidad que la actividad científica del observatorio durante el siglo XIX había sido nula (Babini, 1954, p.152; 1986, p.165). Esta postura, que confiere un pobre papel en la historia de las ciencias en la Argentina para el Observatorio de La Plata, reaparece en varios pasajes de la historiografía de la astronomía local y ha bloqueado un intento más profundo de estudio del carácter de los trabajos y de las disputas interinstitucionales entre los miembros de los observatorios locales. El contrastequeapareceen lasfuentes, y es retomado por la historiografía, es: nivel científico internacional en Córdoba versus falta de idoneidad en La Plata. Conviene, sin embargo, desandar esta representación. Se subraya en este artículo la imbricación de las tareas platenses con una forma de organización de los recursos propia de los astrónomos del Observatorio de París y del Bureau que, a su vez, disputaban la coordinación de los trabajos científicos internacionales del momento. Se mostrará cómo las diferencias mundiales respecto de la manera en que debían promoverse las actividades de los observatorios se manifestaban localmente en la competencia interinstitucional entre los miembros de los dos observatorios que seguían las disyuntivas de los debates internacionales en el área.

En el siglo XIX, las conquistas territoriales y los embates militares, en los límites y al interior de los espacios nacionales, manifiestan, a su vez, la competencia internacional 
por las formas de entramar y comunicar el espacio; pero aún después de ellos, las disputas persistían al interior y en los límites de las expansiones nacionales. La red de comunicaciones, tal es como correos, vapores, telégrafos y ferrocarriles, se hacía cada vez más densa, en tramaba cada vez a más naciones y la heterogeneidad de representaciones para la medición de espacios y tiempos involucrados en la circulación de mercancías y de hombres aparecía como un problema de urgente resolución. Como relata Galison (2003), era una época marcada por disputas diversas en ese sentido. Son algunas de ellas: la unificación de catálogos y mapas cel estes y terrestres, el sistema métrico, la hora unificada y el meridiano de Greenwich. Si bien en las negociaciones para el establecimiento de un sistema de medidas de distancias unificado se impuso finalmente el métrico decimal francés, hubo además una más larga y conflictiva disputa en torno de cómo convenir horas unificadas y su representación espacial trazada sobre un meridiano. Aunque científicos y diplomáticos franceses que habían impuesto el metro pensaban que lograrían nuevos triunfos en otros patrones de referencias temporal es y espaciales, en 1884, cuando sereunieron en Washington las comitivas internacionales que definirían la cuestión de un meridiano único, sólo las de Francia, Brasil y Santo Domingo votaron en favor de un 'meridiano neutral', es decir, que no pasara por Greenwich. Los defensores del meridiano inglés, que trataban de imponerlo como referencia común para todos los relojes y medidas de longitud en el mundo, tenían argumentos de peso: el $72 \%$ de los tonelajes de barcos y fletes del comercio mundial se guiaban por mapas que remitían a Greenwich como arco principal (Galison, 2003). La trama del transporte comercial en general, y del marítimo en particular, era un factor clave en la competencia por las convenciones sobre padrones de medición de tiempo y espacio. Lo mismo puede decirse respecto de las comunicaciones. Galison muestra cómo las disputas sobre definiciones científicas se imbricaban en el intento de comunicar y mapear el mundo y sus aguas a través del tendido de redes telegráficas submarinas. El debate de Washington estaba de hecho ligado a que cada vez más países utilizaban la telegrafía para construir sus mapas, tomando al meridiano que pasaba por sus respectivas capitales como la referencia central.

Como para las sucesivas medidas involucradas en las discusiones sobre patrones espaciotemporal es se utilizaban métodos astronómicos ligados a la geodesia, la rivalidad se prolongó al seno de la propia ciencia astronómica. ${ }^{3}$ Estudiosos del cielo de diversas nacionalidades reivindicaban formas específicas dellevar adelante sus trabajos. Así, por ejemplo, la estrategia que impulsaba desde mediados del siglo XIX el astrónomo germano Argelander, entre otros, para la construcción de cartas y catál ogos cel estes consistía en que personal entrenado intensivamente en la astronometría (medición de la posición y magnitud de los brillos estelares) administrara los recursos de los observatorios y ejecutara los trabajos según las reglas e instrumentos convenidos, de modo que los mapas y catálogos celestes producidos fuesen luego utilizados fuera de los observatorios por quienes los necesitaran para las medidas geodésicas correspondientes. También Gould, discípulo de Argelander, impulsaba esta perspectiva en el observatorio cordobés.

Sin embargo, a fines del siglo XIX, en otros observatorios mundiales, se implementaban formas de acumulación y coordinación de los trabajos que ponían directamente recursos humanos con diversas técnicas de las ciencias conexas a la astronomía a disposición de los 
directores de los observatorios, quienes buscaban intercalar en ellos tareas astronométricas con prácticas geodésicas, cartográficas y topográficas y lograban así aumentar sus recursos. Este era el caso en el Observatorio de París, coordinado por la dirección del Bureau des Longitudes. Boistel (2006) muestra que sus integrantes aprovecharon recursos conjuntos de reparticiones navales e hidrográficas para dar escala a sus proyectos astronómicos. Fue lo que hicieron en las expediciones de observación del pasaje de Venus al convocar para encabezarlas a varios oficiales de la Marina. El director del Observatorio de La Plata era uno de los marinos formados en esta línea y supo articular sensibilidades militares locales sobre la ausencia de mapas adecuados con la ventaja que, según esgrimían los miembros del Bureau, surgía de vincular la astronomía y las técnicas cartográficas y geodésicas dentro del Observatorio. Sin embargo, en Córdoba, los directores sostendrían la línea de intensificación en la construcción de catálogos astronométricos, descartando las interacciones con las ciencias conexas impulsadas por los platenses. Al fin y al cabo, la base de su acumulación de recursos había sido apelar constantemente a la repercusión internacional que habían tenido los catálogos del cielo sur construidos por sus directores siguiendo la estrategia de Argelander.

Se mostrará que este tipo de disputas interinstitucionales e internacionales está oculto detrás de los rótulos de poca monta adjudicados a los trabajos realizados en el observatorio platense.

\section{El Observatorio de Córdoba y la Astronomische Gesellschaft}

El Observatorio de Córdoba fue inaugurado en 1871. La ley de presupuesto general de la Nación de 1870 le había destinado 31.870 pesos fuertes (Chaudet, 1926; Bernaola, 2001; SCA, 1979). Gould dirigió las primeras tareas que tuvieron por objetivo determinar las magnitudes de las estrellas visibles a simple vista y fijar sus posiciones en los mapas, observaciones que se efectuaron a ojo desnudo y se complementaron luego con las real izadas a través del círculo meridiano que llegó en 1872. El resultado era ansiado por el grupo de la Astronomische Gesellschaft, sociedad astronómica encabezada por Argelander, por el simple hecho de que en los observatorios del Norte, donde ya se había adelantado bastante en el reconocimiento del cielo boreal, la mayor parte de las estrellas australes no podían ser vistas. Cuando se fundó el establecimiento cordobés existían sólo cinco observatorios en el hemisferio austral: el del Cabo de Buena Esperanza; el de Melbourne, en Australia; el de Madras, en la India; el de Santiago, en Chile, y el de Rio de Janeiro, en Brasil. En el hemisferio boreal, en cambio, existían cientos de observatorios que habían iniciado sus tareas hacía más de un siglo (Thome, 1906). La investigación dirigida por Gould, siguiendo las reglas de la Astronomische Gesellschaft, fue continuada por el estadounidense Thome desde 1885 hasta 1908.

En conjunto se editaron catálogos que contenían referencias de aproximadamente seiscientos mil estrellas del hemisferio sur. Los registros de las observaciones comenzaron a publicarse en los volúmenes de los Resultados del Observatorio Nacional Argentino desde 1872; en 1879 se publicó la Uranometría argentina con catálogos y mapas que incluían posiciones y brillos de 7.756 estrellas más brillantes que magnitud 7; en 1884, el Catálogo de las zonas 
estelares con más de 73 mil estrellas entreel $-23^{\circ}$ y el $-80^{\circ}$ (Figura 1 ). Todos estos relevamientos pretendían listar y fijar las posiciones y brillos de las estrellas de una manera aproximada, y luego, sobre ellos, se especificaban aún más las mediciones, dando lugar a nuevas publicaciones. Así, en 1886 se publica el Catálogo general argentino con posiciones y brillos de 33.600 estrellas; se editan, en cuatro entregas (1892, 1894, 1900 y 1914), las Zonas de exploración del Córdoba Durchmusterung y se empieza a trabajar en los catálogos de la Astronomische Gesellschaft (AG) (Bernaola, 2001; SCA, 1979) que tomaban sus nombres de homónimos realizados por los discípulos de Argelander en el Norte. Los instrumentos, cronógrafos, fotómetros y demás telescopios del observatorio se correspondían con dichos requerimientos de unidad con los trabajos germanos (Rieznik, 2008).

El trabajo en el Observatorio se especializó en la construcción de catálogos y mapas celestes. Si bien la asociación entre el observatorio cordobés y las expediciones geodésicas y geográficas que necesitaban orientar su trabajo topográfico en territorio nacional no estaba ausente, apenas aparecía ligada a algunas peticiones concretas: para el establecimiento de la hora oficial o por pedidos de ciertas expediciones geográficas. Aunque la iniciativa de Gould había vehiculizado el establecimiento de los primeros puntos de longitud del territorio nacional ${ }^{4}$, el director tenía claro que el Observatorio debía ser administrado por astrónomos y que casi todo el trabajo a realizar requería ejecutores entrenados en la astronometría

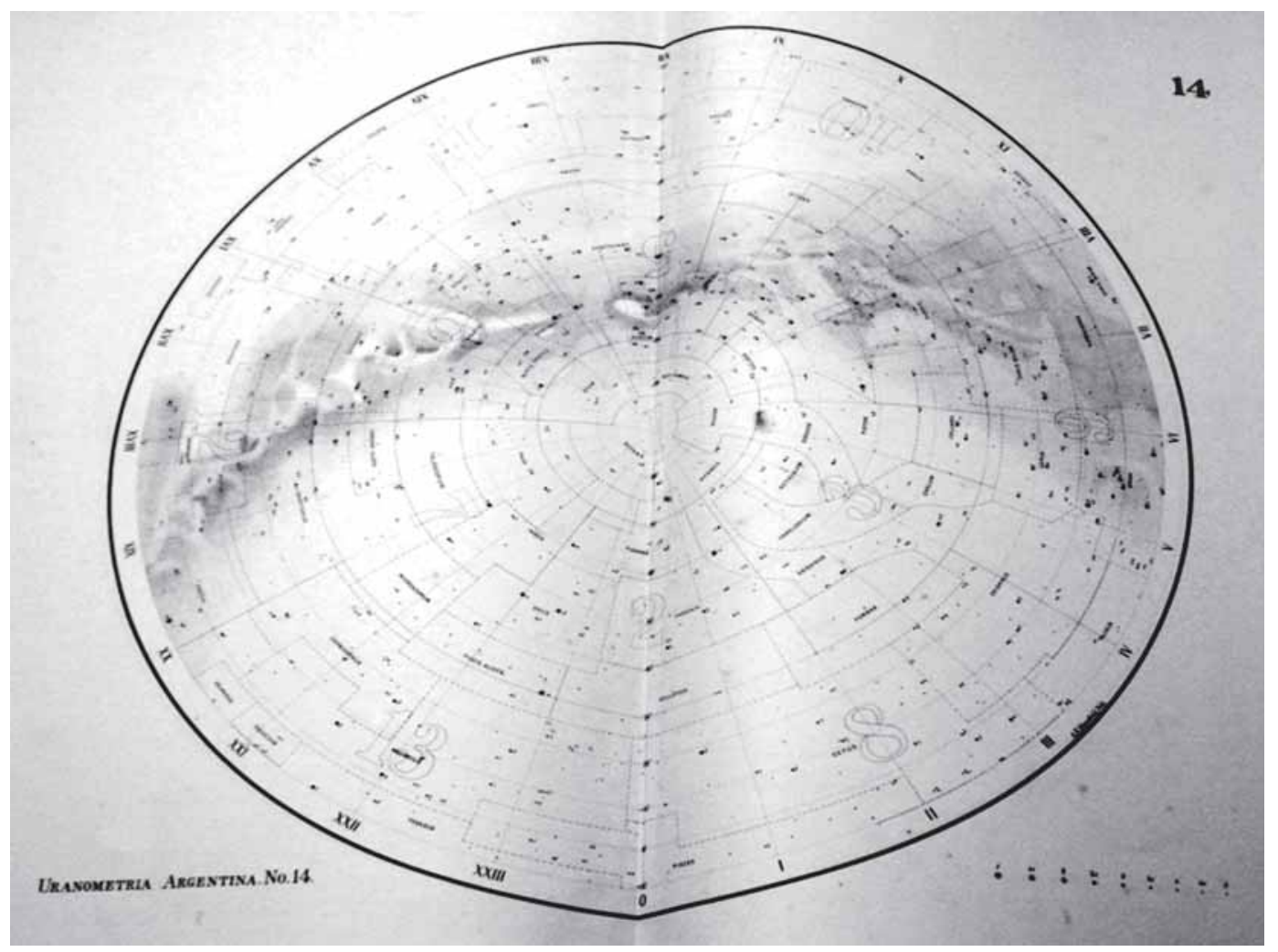

Figura 1: Mapa construido por el equipo de Gould en el Observatorio de Córdoba, extraído de la Uranometría argentina, considerada como continuación de la Uranometría nova de Argelander (Biblioteca Nacional de la República Argentina) 
germana. Si alguno de sus ayudantes se dedicaba a otros menesteres, sus quejas eran constantes, sin importar si se volcaban a la docencia o si se orientaban hacia la meteorología, área que, si bien Gould había contribuido a fundar, quería desligar de las tareas del Observatorio (Rieznik, 2008).

La perspectiva fue sostenida durante la segunda dirección del Observatorio mientras las prácticas cordobesas pasadas se iban cristalizando en productos que circulaban y utilizaban en otros países, mostrando que los criterios de observación y los cálculos impartidos habían sido los requeridos. La circulación internacional de los resultados del Observatorio era siempre esgrimida por sus directores para requerir fondos o aumentos presupuestarios.

\section{El pasaje de Venus y el Bureau. La fundación del Observatorio de La Plata}

En 1881, Buenos Aires había sido declarada por ley distrito federal y en 1882, La Plata fue transformada en la capital de la provincia de Buenos Aires. La ley autorizaba al poder ejecutivo a invertir 70.350 mil pesos moneda nacional en la construcción de los edificios públicos de la ciudad platense, a la vez que destinaba a la edificación de un observatorio astronómico la porción más pequeña de los fondos: 200 mil pesos. Por otra parte, en el decreto provincial del 1 o de noviembre de 1881 , el gasto presupuestario para ayudar a la comisión internacional que organizaba la observación del pasaje de Venus se había justificado porque sus instrumentos servirían "en el observatorio astronómico quetieneel gobierno el proyecto de fundar" (SCA, 1979, p.9).

Las primeras bases materiales para el Observatorio estuvieron así financiadas por medio dela misión para el pasaje de Venus. Desde 1761, varias misiones coordinadas desdedistintos puntos de la Tierra habían utilizado las mediciones del tránsito de Venus delante del Sol para deducir la distancia Tierra-Sol. En 1869, los astrónomos germanos habían impulsado la creación de comisiones gubernamentales para la observación del pasaje de Venus de 1874, interés compartido por sus colegas en los Estados Unidos, Francia, Rusia, Italia y Holanda. En aquella ocasión, la fotografía fue utilizada de manera generalizada en servicio de la astronomía pese a las dudas generadas respecto de su efectividad. Mucho se debatió luego sobre qué potencialidad tenía la propia observación del pasaje (González González, 1989; Orchiston, Dick, Love, 1998; Lankford, 1987). Para entender el impulso dado por determinadas instituciones a las misiones para la observación de los pasajes de Venus, tanto en 1874 como en 1882, debe atenderse a su historia concreta.

En el caso del Bureau des Longitudes de Francia, su dirección aprovechó el pasaje de Venus de 1874 para mostrar al gobierno su utilidad y sus capacidades para el desarrollo científico y junto a miembros de la Academia de Ciencias hizo proliferar las misiones para las observaciones, estrategia ligada al intento de recuperar el manejo de los recursos del Observatorio de París sobre los que la dirección del Bureau había perdido el dominio antes de mediados del siglo XIX (Boistel, 2006).

Para dirigir las expediciones, fueron convocados oficiales de la Marina, entre los cuales estaba el almirante Amédée Mouchez, militar de carrera en ascenso que supo aprovechar la oportunidad. Mouchez ya había desarrollado técnicas de observación astronómica y las utilizaba muy especialmente en la hidrografía, haciendo determinaciones geográficas para 
la rectificación de las cartas náuticas. Desde 1873 era miembro del Bureau des Longitudes y luego de la experiencia del pasaje de Venus, alegando querer instruir mejor en astronomía a los miembros de la Marina, propuso la creación de un observatorio de Marina bajo la órbita del Bureau. La dirección de la institución avaló la idea y volvió a tener jerarquía en una red queincluía observatorios, formación demarinos, exploraciones y viajes cartográficos.

Entre otras campañas encaradas en el Bureau a fines del siglo XIX, se encuentran la medición telegráfica y astronómica de diferencias de longitudes entre París, Berlín y Bonn en 1877, la cartografía magnética general del globo entre 1895 y 1896 y la participación en los trabajos del Departamento de Guerra para la medición de un arco meridiano en Francia. En 1878, Mouchez fue nombrado director del Observatorio de París, momento considerado como la culminación de la vuelta al centro de la escena científica del Bureau (Boistel, 2006).

En la Argentina, la fundación del segundo observatorio sostenido por fondos estatales estuvo ligada al impulso que les dio la dirección del Bureau a las misiones del pasaje de Venus. Aunque el Observatorio de Córdoba participó también en las observaciones de 1882, su actividad se oponía a la estrategia francesa y su director informaba su parecer respecto del pasaje de Venus de 1882 haciendo un relato histórico de estos pasajes desde el del año 1769 y resaltando varias veces la desilusión de las expediciones organizadas en 1874:

En verdad la marcha rápida de la ciencia en los últimos veinte años ha aumentado las exigencias en cuanto a la exactitud; y pareceya demostrado queel método que hace un cuarto desiglo era considerado como el único dotado con la exactitud necesaria tieneque ceder sus pretensiones. Las observaciones micrométricas delosasteroidesen sustiempos de oposición, las determinaciones físicas de la vel ocidad de la luz, las medidas dela paralaje diurna del planeta $M$ arte, aun las investigaciones numéricas de las perturbaciones dela Luna, proporcionan valoresmás conformes entresí quelos deducidos del pasajedeVenus (Gould, nov.1882).

Sus comentarios estaban basados en iniciativas prácticas. Las actividades alternativas señaladas eran las que se llevaban adelante en el Observatorio, especialmente una serie de observaciones del asteroide Flora del año 1873. Además, Gould estaba expresando una opinión sostenida en el seno de la comunidad astronómica estadounidense respecto de lo anticuado del método y aunque sabía que había misiones extranjeras que observarían el pasaje desde territorio argentino, Gould opinaba en relación con dicha persistencia:

Lacuestión desi deben mandar nuevas expediciones para observar el pasajedediciembre de 1882 se ha discutido seriamente en todas partes. Creo que son pocos los astrónomos quecreen ahora que se puede esperar mucho de ellas. Sin embargo parece quehabrá tales expediciones desdevarios países, aunqueen una escal a muy reducida de la quese adoptó en 1874. No es tanto que esperen mucho, cuanto que no se animan a tomar la responsabilidad de desperdiciar la oportunidad. ... hay poco que pueda conseguirse de observaciones semejantes... Por otra parte, las gran des obras quetenemos emprendidas exigen una fuerza mucho mayor de la que podemos disponer. Así creo que, dejando éstas para hacer los largos y costosos preparativos necesarios para observaciones de la primera clase, pasaríamos un perjuicio a la ciencia, dejando la sustancia en busca de una sombra (Gould, nov.1882). 
Gould era terminante respecto del escaso aporte científico de la observación y del desperdicio de recursos que implicaría. Efectivamente, en 1882, en la convención internacional de astrónomos de París que preparaba los detalles de la observación, la mayoría de los directores de los observatorios del continente europeo, exceptuando los franceses, había declarado defectuoso el método fotográfico y había retornado al método visual de contactos, aunque tampoco consideraban que éste fuese muy preciso. Las discusiones muestran que incluso los principales impulsores estadounidenses de las observaciones de Venus dudaban respecto de la utilidad del evento (Orchiston, Dick, Love, 1998; Lankford, 1987). Sin embargo, para los directores de los principales observatorios involucrados, la misión significaba partidas presupuestarias extras que servían para acumular recursos para las tareas de los observatorios ${ }^{5}$ y en el caso francés, además, aseguró a los miembros del Bureau des Longitudes la reunión, ampliación y organización de una variada gama de recursos humanos y materiales y, en el corto plazo, volver a imponer su gravitación sobre el observatorio parisino.

Pero las afirmaciones de Gould eran las de quien disponía de una base material armada sobre otras redes de trabajo ya que había centralizado recursos en función de su papel jugado en los procesos internacionales de elaboraciones astronométricas coordinadas por los miembros de la Astronomische Gesellschaft. Su experiencia estaba ligada al entrenamiento para la homogeneización, precisión y extensión de los catálogos celestes hacia el Sur y sabía usar muy bien los dichos internacionales respecto de la calidad de sus productos para obtener fondos para el Observatorio. De todos modos, llevó adelante algunas observaciones para el pasaje, aunque no utilizó un equipo especial y lo único que hizo fue, como dice Hodge (1971), no caer en una escandalosa negligencia ante la atención pública que el evento había suscitado. Sin embargo, expresó clara y reiteradamente su disgusto por esta distracción de sus tareas centrales (Rieznik, 2008).

Esta evaluación era muy distinta de la hecha por el francés, ex teniente de navío, Beuf, desde la provincia de Buenos Aires. Estaba en el país desde la primera presidencia de Julio Roca (1880-1886), invitado por el ministro de Guerra, Carlos Pellegrini, para reorganizar la Escuela Naval Argentina a cuyo frente se encontraba entonces (SCA, 1979, p.10). Militar retirado de la Marina francesa y de la dirección del Observatorio de la Marina de Tolón, se dedicó a la docencia en el Colegio Nacional de La Plata y en la cátedra de Geodesia y Topografía de la Facultad de Ingeniería de Buenos Aires y fue miembro del Instituto Geográfico Militar. Integraba las primeras generaciones de marinos franceses formados entre los astrónomos del Bureau que seguían la estrategia de acumular fondos, poniendo bajo coordinación de los observatorios recursos de diversas reparticiones militares y estatales. Era, además, miembro corresponsal del Bureau y uno de los principales impulsores de los preparativos para las misiones del pasaje de Venus en la Argentina.

El gobierno de la provincia de Buenos Aires aprobó conformar un equipo de trabajo para presupuestar los gastos de la misión del pasaje de Venus, encontrar un lugar adecuado y preparar personal argentino para las observaciones. Este equipo estaba integrado por el propio Beuf, por el presidente del Departamento de Ingenieros y por el vocal de la Sección de Geodesia de dicho departamento. Fueron convocados para las tareas, ingenieros provenientes de la Facultad de Ingeniería de la Universidad de Buenos Aires. Además, el 
Ministerio de Marina de Francia había autorizado al teniente de navío Edouard Perrin a venir al país para dirigir la expedición (SCA, 1979, p.10). La preocupación de la dirección del Bureau y del observatorio parisino por la formación de técnicos que entrecruzaran habilidades astronómicas, geodésicas y topográficas y por el aprovechamiento de los recursos de diversas reparticiones era una característica de las actividades involucradas en la observación del pasaje de Venus que perduraría en las del observatorio platense.

Los instrumentos necesarios se compraron en Francia y conformaron la primera base instrumental del futuro Observatorio de La Plata. Beuf encargó en la casa Gautier de París la construcción de un telescopio ecuatorial de $216 \mathrm{~mm}$ de abertura y 3,10m de distancia focal para la realización de la tarea con la intención de homologar los resultados a los del Observatorio de París. En Francia, Mouchez supervisó su construcción (SCA, 1979, p.10). En tanto Perrin se encargaba de dirigir la coordinación del equipo instalado en Bragado, Beuf colaboraba desde Buenos Aires y se intercambiaban señales telegráficas (Perrin, 1883; Mouchez, 1882). Ambos habían trabajado juntos en 1878 en la publicación de un artículo sobre mediciones de longitud en el mar (Beuf, Perrin, 1878) y ahora coordinaban un trabajo en el que involucraban a los ingenieros y militares argentinos encargados de auxiliarlos en las tareas. La observación y el registro del pasaje eran mediados por una forma de organización de los recursos que se alineaba en la red de trabajo del observatorio parisino y del Bureau.

Gould había dedicado su primera obra en la Argentina al astrónomo germano Argelander porque quería asociar su trabajo con los de la red impulsada por su maestro; Beuf dedicó a Mouchez su Curso de geodesia y topografía de 1886 por idénticos motivos:

Le dedico esta obra como homenaje de mi vivo reconocimiento por las numerosas muestras deaprecio con las que usted no ha cesado de honrarme. La he escrito en un país que ha sido el escenario de uno de sus más importantes trabajos hidrográficos, y por el queusted ha conservado la más sincera simpatía. Leha ofrecido constantemente pruebas de poner a su servicio su eximia experiencia y su celo infatigable respecto de todo lo que concierneal progreso delas ciencias: estoy complacido por la ocasión que se me ofrece de poder manifestarlo públicamente. Le guardo un profundo respeto, Almirante. Su incondicional, F. Beuf (Beuf, 1886, p.7). ${ }^{6}$

Consolidando esta perspectiva, Beuf intervendría explícitamente del lado francés en la disputa internacional sobre el meridiano de Greenwich. En el libro con el que enseñaba Geodesia en la Universidad de Buenos Aires, argumentaba respecto de la decisión de 1884 que:

\begin{abstract}
El resultado delas discusiones fuela adopción del meridiano de Greenwich como inicial de las Iongitudes... los representantes de Francia tuvieron que apartarse de la discusión y de los votos, después de haber hecho esfuerzos inútiles para hacer adoptar por la asamblea el principio de un meridiano neutral como origen de las longitudes, y esta abstención de parte de un país, que cuenta con tan valiosos trabajos geográficos e hidrográficos, hace que se pueda considerar el resultado de la reunión como muy comprometido (Beuf, 1886, p.46; cursiva en el original).
\end{abstract}

La opinión de Beuf era una decisión política propia de una de las redes de trabajo que intervenían en la competencia internacional respecto de lasformas derepresentar el territorio 
que se ocupaba y comunicaba. En la Argentina, avanzaban la ocupación, la comunicación y el control del territorio junto a la extensión de las vías férreas y los tendidos telegráficos. En 1879, el general Roca, entonces ministro de Guerra del presidente Nicolás Avellaneda, encabezó las divisiones militares de una campaña que tenía como objetivo ocupar territorios que se encontraban fuera del control político, económico y administrativo del Estado, tanto hacia el sur como hacia el oeste de Buenos Aires; nueva incorporación de tierras que, matanza indígena de por medio, creaba ahora un espacio disponible para entramarlo de transportes y comunicaciones, a la vez que lo abría a la factibilidad de enlazarlo con el mercado mundial.

En los años posteriores se avanzó en los procesos de ocupación y comunicación del territorio nacional; las vías férreas se extendieron, las señales telegráficas se multiplicaron, el comercio internacional impulsó el aumento de la navegación en los puertos y los departamentos topográficos intentaron determinar los límites provinciales que parecían afirmarse como marco estable para la acumulación del capital. ${ }^{7}$ Las nuevas actividades de dominio del espacio empezaron a cobrar importancia en los discursos militares; es lo que se registra en la década que se inicia en 1880. La unificación de las antiguas cartografías, registros catastrales y mapas topográficos era una de las tareas pendientes aludidas. Carla Lois (2004) señala que aunque en rigor la falta de relevamientos era general y no se limitaba a las áreas bajo dominio indígena, los discursos de las nuevas empresas cartográficas, que pretendían centralizarse en el Estado, planteaban que dicha tarea era en esos territorios una necesidad indiscutible e impostergable. Del mismo modo se consideraba la empresa militar que se imponía sobre las tierras indígenas. Resultaba de ello una argumentación circular: por un lado, para ser cartografiados, esos territorios debían ser conquistados militarmente; por el otro, la expansión militar y la ampliación del territorio dominado en forma efectiva requerían la delimitación política y la subdivisión catastral para la asignación de la propiedad de la tierra y la organización del sistema tributario.

La asociación de Beuf con el director del observatorio parisino cobra relevancia en medio de una creciente sensibilidad militar respecto de la ausencia de mapas adecuados y también frente al problema más general de las heterogeneidades que todavía subsistían dentro del espacio estatal que ahora se predicaba como unificado de pesos y medidas, de monedas, de horas y distancias. En sus publicaciones, los miembros del Bureau atendieron especialmente a la unificación de estas convenciones en la propia Francia. Por ejemplo, la heterogeneidad horaria fue un tema debatido en las publicaciones francesas y se problematizaba también en la Argentina, donde, en varias provincias, se marcaban tres horarios diferentes, según fuesen ofrecidos por las iglesias, las reparticiones públicas o las empresas ferroviarias. El intendente de Rosario de entonces, Gabriel Carrasco (1893, p.49), decía en 1893 respecto de la situación de 1891: “Tan grande llegó a ser el desorden que la Municipalidad, a nuestra indicación, tomando la iniciativa de la unificación horaria de la República Argentina, dio una ordenanza declarando hora legal en el municipio la de Córdoba, ciudad que, por encontrarse en el centro de la República y tener observatorio astronómico, está perfectamente indicada para dar la hora en su país".

Carrasco fue nombrado ministro de Agricultura, Justicia e Instrucción Pública de la provincia de Santa Fe e impulsó una circular a los gobiernos de las demás provincias 
proponiendo la unificación horaria; tras obtener una respuesta favorable, planeó impulsar un proyecto de ley nacional. Beuf apoyó decididamente la idea de Carrasco, quien en sus escritos remitía a los avances científicos de las sociedades astronómicas francesas en el área de la unificación temporal y finalmente, por decreto del 31 de agosto, se establecía la hora oficial para las líneas férreas: la del meridiano de Córdoba. El 25 de septiembre de 1894, el gobierno nacional promulgaría la ley correspondiente que establecía idéntica hora oficial para las entidades públicas de todo el país.

En el marco descripto, que derivó en diversos intentos políticos, administrativos y económicos de unificación espacial y temporal, había aparecido la primera mención a algún tipo de base material destinada a la construcción del Observatorio de La Plata. Finalmente su personal fue organizado en 1885 en la órbita del Ministerio de Obras Públicas de la provincia y, como en el caso del observatorio cordobés, la historiografía de las ciencias prestó importancia a los discursos de los gobernantes en relación con las primeras tareas del Observatorio. Si el observatorio cordobés fue entendido como un producto de la obra civilizatoria de Sarmiento, del Observatorio de La Plata se dijo que "nació a impulsos de la voluntad creadora de Dardo Rocha" (SCA, 1979, p.8). Era el gobernador de la provincia y había alegado, respecto del nuevo observatorio, que estaba interesado en "hacer marchar al mismo tiempo el rápido desarrollo de las riquezas naturales de la República Argentina y el de las cual idades morales e intelectuales de sus habitantes, resultado que puede obtenerse principalmente extendiendo de más en más el gusto por el estudio de las ciencias en todas sus manifestaciones" (Rocha, 1883, citado en SCA, 1979, p.9).

Sin embargo, analizando las medidas impulsadas por Dardo Rocha se ve que la cuestión era más concreta: pretendía ligar el estudio astronómico a necesidades de relevamientos cartográficos de la provincia. Esto se explicitaba en la ley del 22 de noviembre de 1883 que firmó. Allí instaba a determinar la situación geográfica de cincuenta puntos diferentes de la provincia con el objeto de servir a la elaboración de una carta geográfica. Nombraba como primer director del Observatorio, con un sueldo de cuatrocientos pesos mensuales, a Beuf, quien debía contratar al personal necesario para las operaciones geodésicas y astronómicas. Beuf sigue entonces los lineamientos aprendidos en Francia: no trae a un grupo de ayudantes extranjeros, como había hecho Gould, sino que se vincula con integrantes de instituciones locales interesadas en ligar la astronomía con la geodesia, la topografía y la hidrografía. A ese fin convoca como ayudantes a ingenieros de la Facultad deIngeniería de BuenosAires y a miembros dela Escuela Naval. El argentino queremplazaba a Beuf en su ausencia, durante los primeros años, era teniente de fragata.

A diferencia del caso cordobés, en el cual las tareas centrales seguían los criterios de organización de los astrónomos germanos que construían catálogos, el foco de los trabajos en el platense aparece ligado a la organización de tareas geodésicas y cartográficas en las que se utilizaban los catálogos y efemérides ya construidos por la astronometría.

El 2 de abril de 1886, Carlos D'Amico, el nuevo gobernador de la provincia, vuelve a insistir en un decreto sobre las tareas que se debían realizar con los fondos presupuestarios destinados al observatorio: que se procediera a "Ias operaciones geodésicas y astronómicas necesarias para el levantamiento del mapa de la Provincia" (SCA, 1979, p.16) y ordena al Observatorio vincular las habilidades astronómicas a las operaciones geodésicas y 
cartográficas. Los primeros instrumentos encargados en Francia por el observatorio platense eran los que se iban a utilizar para los trabajos geográficos encomendados, es decir, instrumentos magnéticos y anteojos de pasaje.

Aunque las redes de trabajo de la astronometría internacional no parecían asignarle a Beuf ninguna tarea específica de investigación después de la observación del pasaje de Venus, en la institucionalización de la astronomía en el nivel internacional había un tema que había escalado hasta convertirse en uno de los motores de la circulación y producción astronómica de esos años y es precisamente en este ámbito en el cual Beuf publicó los resultados en los Comptes Rendus franceses. Se trataba del problema de la determinación de longitudes en todo el Globo. En línea con estas tareas geodésicas, durante la dirección de Beuf, se llevaron adelante diversos trabajos para determinar la longitud del observatorio, haciendo observaciones de ocultaciones de estrellas por la Luna. Por otra parte, estos intentos de determinación atendían a la preocupación francesa y local de establecer una unificación horaria y permitieron informar la hora al público y al puerto de Ensenada.

El decreto de 1886 agregaba además como tarea la instalación de un servicio meteorológico y el Observatorio de La Plata comenzó a publicar los Anales Meteorológicos, numerosas tablas, día por día, con observaciones de las 15 estaciones de la provincia. El gobernador autorizaba la adquisición de instrumentos adecuados que se comprarían en Francia para tender a la consolidación de un servicio meteorológico provincial. Como en el caso del instrumental para la observación del pasaje de Venus, la compra sería asistida por Mouchez. A diferencia de lo que pasaba en el Observatorio de Córdoba, la meteorología no era considerada por su director como un área que debía mantenerse aparte para no entorpecer las tareas fundamentales de la astronomía. Es así como la primera se convierte durante largas etapas en la parte sustancial de las publicaciones del Observatorio. El gobierno provincial decía además que uno de los "cometidos de mayor importancia encomendados al observatorio" de La Plata consistía en instalar el servicio meteorológico provincial (SCA, 1979, p.8). La red quedó establecida en 1893 y la atención a cada una de las 17 estaciones fue confiada a los jefes de las oficinas del telégrafo de la provincia. Nuevamente se implementaba la modalidad aprendida en el Bureau para la coordinación de recursos externos en tareas dirigidas por el Observatorio: en cada una de las estaciones se hacían tres observaciones por día sobre la base de las cuales se editaba un boletín meteorológico diario. Entre 1893 y 1902 se publicaron 3.286 boletines.

Desde la colaboración ofrecida por la provincia de Buenos Aires para las observaciones del pasaje de Venus, el propio director del Observatorio de París seguía de cerca las tareas en la Argentina y en sus artículos para la Academia de Ciencias francesa o para el Bureau des Longitudes daba cuenta detal ladísima de todos los instrumentos encargados por el gobierno argentino en Francia. Cuando el proyecto del Observatorio aún estaba elaborándose, Mouchez (1886) comentaba los que consideraba excelentes emprendimientos de la institución platense: la intención de enviar la señal horaria distribuida y las 14 estaciones meteorológicas que, a la vez, enviarían los datos obtenidos. Decía además que Beuf era asistido por jóvenes e inteligentes colaboradores argentinos que habían sido formados por él durante años como profesor de astronomía y geodesia en la Facultad de Buenos Aires. 
Por otro lado, estaba muy bien informado sobre los nuevos avances territoriales del Estado Argentino y por eso también felicitaba a Beuf porque tomaría en sus manos el levantamiento geodésico del vasto territorio dela provincia y colaboraría en la medida de un arco meridiano que incluiría a los territorios del Chaco y de la Patagonia. Entonces, al tiempo que difundía Ios nuevos avances militares y administrativos del Estado Nacional Argentino y vinculaba directamente estos emprendimientos con las tareas que debían ser coordinadas por el observatorio, reivindicaba este quehacer como integrante de la división de trabajo internacional y lo mencionaba como una cuestión de utilidad práctica inmediata para el mejor conocimiento de la forma de la Tierra debido a que sólo se poseían en el hemisferio sur mediciones de un pequeño arco de meridiano en el cabo de Buena Esperanza. Mencionaba al detalle las medidas topográficas y geodésicas ya avanzadas en el territorio nacional argentino y aconsejaba métodos para continuar con la tarea de homogeneización de sus representaciones espacial es. ${ }^{8}$ Proseguía dicien do que la carta que se preten día construir permitiría establecer con certeza las fronteras, los límites administrativos y aquellas grandes extensiones para las eventuales colonias agrícolas, para establecer el catastro, para el estudio de las posibles vías de comunicación y para indagaciones geográficas e hidrográficas, todas medidas, según él, encaminadas a que el territorio hasta entonces 'desierto' se poblase con una febril actividad. Mouchez sabía perfectamentequeno setrataba literal mentededesiertos; él mismo explica que el primer período de pacificación en el país se había logrado después de purgar el territorio de las "hordas de indios que lo ocupan en estado salvaje" (p.419) y, continúa el escrito, atribuyendo el estado de barbarie de las repúblicas sudamericanas de la primera mitad del siglo XIX a las continuas y deplorables guerras civiles que se perpetuaban por la dificultad de las comunicaciones, la inexistencia de los vapores y los telégrafos y la ausencia del elemento extranjero "naturalmente pacifico y civilizador"10 (p.420). Ahora, entonces, todo era solucionable gracias a la fluida comunicación creada recientemente entre Europa y América del Sur. Mouchez pronosticaba que el Observatorio de La Plata aseguraría al país su integración a los trabajos científicos que eran el honor de las “naciones avanzadas"11 (p.421) y a los agentes más activos de la civilización. Como parte recíproca de este impulso, Beuf en su libro insistía también en la idea de la medición del arco meridiano:

Siendo la República Argentina el país mas apropiado del mundo, por la topografía de sus suelos, para la medición de un arco de meridiano o de paralelo, puede contribuir poderosamente a sancionar la forma definitiva de la Tierra: y por mi parte hago votos para que las dificultades, más aparentes que reales, y recién solevantadas, para impedir que el país entre con toda resolución en el sendero glorioso de la Ciencia universal, prestando su cooperación paraun objeto detan trascendental importancia, desaparezcan delante de las exigencias del verdadero progreso. Abrigo la confianza, quizá demasiado halagüeña, de que la obra actual contiene todos los el ementos necesarios para poner al hombre estudioso en condiciones de tomar una parte hon rosa en la operación aludida, colocando así a la República Argentina al nivel de las naciones más adel antadas bajo el punto de vista científico. Esta es la razón que me ha guiado para tratar con detención todo lo que se relaciona con la medida de un arco de meridiano, inspirándome al efecto en losúltimos progresos efectuados hasta la fecha en la al ta Geodesia y que están expuestos periódicamente en los ‘Comptes Rendus de les Conférences de la Comisión Geodésique Internationale' (p.9). 
La red de trabajo es una y otra vez afirmada en publicaciones francesas y locales y el Observatorio de La Plata publica 14 anuarios entre 1887 y 1900. En el primer número se encuentran dos tipos de informaciones. Un primer grupo habla de obras donadas al Observatorio, del personal, de la ubicación de los observatorios meteorológicos y de al gunos fragmentos de datos astronómicos observacionales, como, por ejemplo, ocultaciones de estrellas por la Luna, posiciones de los planetas en el cielo, posiciones de las estrellas, informaciones generales de astronomía y meteorología, cál cul os de meridianos y longitudes y tablas de equivalencias entre diferentes escalas internacionales. El primer tipo de información correspondía, entonces, a la administración de recursos del Observatorio y al registro de tareas observacionales propiamente astronométricas y geodésicas. Estas publicaciones apuntaban, también, a ofrecer datos astronómicos útiles para trabajos de agrimensura. Lo distintivo de la edición platense, en comparación con las que se publicaban en Córdoba, era el segundo tipo de informaciones vertidas en el anuario que trataban sobre el valor legal de las monedas nacionales e internacionales, datos estadísticos acerca de censos poblacionales, escolaridad pública y privada, movimientos migratorios en la provincia de Buenos Aires, movimientos de ferrocarril de la provincia en 1887 y tablas de equivalencia de pesos y medidas, diferencia que no pudo ser explicada por los historiadores. Esta era una de las publicaciones que Babini (1954, p.152; 1986, p.165) consideró que reflejaban en realidad que la actividad científica del Observatorio durante el siglo XIX había sido nula.

Como se dijo, esta evaluación negativa se rastrea en las fuentes y reaparece en varios pasajes de la historiografía y ha bloqueado un intento más profundo de estudio de los motivos de la fundación del observatorio platense. En realidad, también estas publicaciones ponen de relieve la imbricación de las tareas platenses con una forma de organización de los recursos propia de los astrónomos que en Francia disputaban la coordinación de los trabajos internacionales del momento. De hecho, es imposible entenderlas sin hacer alusión a la especificidad de una de las publicaciones científicas francesas de la época: los anuarios platenses pretendían ser análogos al Annuarie du Bureau des Longitudes. Decía un astrónomo francés de entonces:

Ciertamente, el Anuario que el Sr. Beuf, director del nuevo observatorio de La Plata, acaba de publicar será acogido favorablemente. El Sr. Beuf ha procurado tomar como modelo al Anuario del Bureau des Longitudes, reduciéndolo un poco. 160 páginas están consagradas a los datos astronómicos propiamente dichos; el resto del volumen (260 páginas) está ocupado por los pesos y medidas métricas y por su comparación con las antiguas medi das de las diferentes provincias, por estadísticas, geografía y meteorología (Revuedes Publications..., 1887, p.291). ${ }^{12}$

No sólo la publicación platense emulaba al Annuaire du Bureau des Longitudes, sino que además astrónomos franceses leían, divulgaban e impulsaban las publicaciones y tareas del observatorio platense (Le nouvel observatoire..., 1884). Para que no queden dudas de que la heterogeneidad de la publicación no era una mala idea de Beuf, se cita el contenido de su equivalente francés, el Annuaire du Bureau:

1. Sr. Mouchez. Creación de un observatorio de estudio en el parque Montsouris por el Bureau des Longitudes. 
2. Sr. Faye. Las tormentas y la formación de granizo. Teorías, investigaciones, verificaciones.

3. Los elementos astronómicos más usual es obtenidos de la Connaissance des temps.

4. Artículos y tablas estadísticas.

5. Estaciones, calendariosjulianos, gregorianos, republicanos, israelitas, musulmanes. Salidasy puestas del Sol y pasajes por el meridiano del Sol, de la Luna, y de los planetas, fenómenos astronómicos, duración del día astronómico, aspecto de los planetas, eclipses, posición delas estrellas, tiempossiderales, efemérides. Cál culo delasmareas: horarios de plena mar en Brest y en al gunos grandes puertos de Europa.

6. Tablas delos principal es elementos del sistema solar, planetastelescópicos entre Marte y Júpiter.

7. Pesosy medidas en Francia, conversiones entrelas diferentes unidades de medida, medidas de otros países.

8. Monedas: monedas francesas, fabricación de monedas, tablas según la naturaleza de las piezas, tablas deamortización y de interés.

9. Estadísticas: población deParísy deFrancia, movimientos superficiales de población, mortalidad, consumo.

10. Posición delas coordenadas geográficas de diferentes puntos del globo, tabla de las alturas de las principales montañas del mundo.

11. Diversastablas defísica y de termodinámica.

12. Planchas (4 en página dobley 2 desplegables): Vista del Observatorio de la M arina desdeel Parque deM ontsouris. Carta de las líneas deigual declinación magnética en Francia en 1875. Una plancha, en página doble, del revólver fotográfico de Janssen (interior). Carta delas líneas deigual declinación magnética en Francia en 1876. Carta de los partidos de Francia y de los Países Bajos asolados por la tempestad del 13 de julio de 1788. Carta general de la tempestad del 13 de julio de 1788 (Bureau des Longitudes, 1877, p.5 $)^{13}$.

En cuestión de heterogeneidad de los contenidos de la publicación, la institución francesa era la guía de las ediciones platenses. En Francia, la propia compilación y divulgación de datos jugaba un papel fundamental: mostraba que los fondos estatales dedicados a financiar la institución tenían utilidad práctica en la resolución de heterogeneidades diversas que se querían padronizar y contribuía así a la afluencia de recursos que permitían sostener las tareas específicas delas disciplinas astronómicas y conexas. En la Argentina, la publicación no sólo daba cuenta del interés de la institución platense en áreas particularmente sensibles a los intentos de unificación estatal, sino que, además, mostraba que se estaban siguiendo los lineamientos científicos internacionales de las instituciones francesas, perspectiva que en la época parecía una de las alternativas para estar a la cabeza de las iniciativas de coordinación de las tareas astronómicas internacionales.

\section{La Carte du Ciel. El debate Córdoba-La Plata}

Hasta 1886 parecía que en el observatorio platense se avanzaría en relación con aplicaciones geodésicas y topográficas de la astronometría y que así su director entraría en la red de trabajo del observatorio parisino y del Bureau, pero que en La Plata no se 
elaborarían resultados astronométricos de relevancia internacional. Esto cambió en 1887 cuando Beuf fue invitado por Mouchez al Primer Congreso Astrográfico Internacional en París para la elaboración de la Carte du Ciel. El papel más renombrado jugado por el Observatorio de París en la astronometría fue el de coordinar la elaboración de dicha carta. Su origen se remonta a 1882, año en que el astrónomo David Gill obtuvo desde del cabo de Buena Esperanza una fotografía del Gran Cometa y, al ver el fondo de la placa repleto de estrellas, concibió la idea de reproducir y archivar en la placa fotográfica todas las estrellas del cielo (Reyes, 1932). Gill envió copias en papel de las fotografías a Mouchez, quien a su vez las remitió a la Académie des Sciences con una nota explicativa en la que aludía a las brillantes perspectivas que se vislumbraban para obtener cartas estelares por medio de la fotografía. Poco después, el director del observatorio parisino indujo a los hermanos Paul y Prospér Henry a que se dedicaran a la construcción de lentes apropiadas para la fotografía estelar (Reyes, 1932) y, así, los dos astrónomos construyeron un objetivo de $16 \mathrm{~cm}$ con el que, en 1884 , obtuvieron una imagen de una zona de la Vía Láctea que enviaron a Mouchez. Con el visto bueno del director, construyeron un nuevo aparato con un objetivo de $33 \mathrm{~cm}$ cuya parte mecánica fue encargada a Gautier. Cuando se obtuvieron placas más nítidas, Mouchez planteó la idea de confeccionar una carta del cielo por medio de la fotografía con la colaboración de observatorios de todo el mundo: creía que si la perspectiva se confirmaba se podría poner a su observatorio a la cabeza de un siguiente plan de vasta escala para la homogeneización de los resultados astronométricos. Como en el caso del pasaje de Venus, serían miembros del Bureau des Longitudes, junto a la Academia de Ciencias, quienes se encargarían en Francia de propiciar la iniciativa llamada Carte du Ciel que se proponía catal ogar todos los cuerpos visibles de la cúpula cel este. La coordinación requería no sólo estandarizar la construcción de los instrumentos de trabajo, sino también controlar nuevas destrezas que debían ser utilizadas con instrumentos antes desconocidos. Se cursaron invitaciones a integrantes de sociedades científicas y a observatorios de todo el mundo quetendrían queacudir a París el 16 de abril de 1887, cuando se realizase el Congreso Astrofotográfico Internacional. M ouchez ya había puesto en movimiento recursos humanos de secciones hidrográficas, navales y geodésicas de Francia para los trabajos de su observatorio; si entonces lograba movilizar a astrónomos de otros Estados nacionales para que tomasen placas desde sus observatorios, conseguiría que la centralización de recursos se evidenciara en resultados tangibles en el plano de la competencia internacional y la dirección del Bureau podría así, literalmente, fotografiar el triunfo.

Mouchez propuso la incorporación del observatorio platense al esfuerzo coordinado de diversos países para este relevamiento fotográfico y cursó la invitación. Mediante un decreto, el gobierno de la provincia de Buenos Aires asignó a un ingeniero argentino para que acompañara al director en su viaje como ayudante de astrónomo. El evento se realizó con la presidencia del ministro de Asuntos Exteriores francés y la asistencia de 56 científicos de todo el mundo (González González, 1989). En marzo de 1888, integrantes de 13 observatorios habían encargado la construcción de instrumentos: Potsdam, Oxford, Melbourne, Sydney, Rio de Janeiro, Santiago de Chile, San Fernando, París, Burdeos, Tolousse, Argel, Tacuyaba y La Plata. En 1889 se sumaron a la misión Greenwich, Roma, Catania, Helsingfors, Argel y El Cabo. A La Plata eran Ilevados, desde Francia, no sólo los 
instrumentos científicos y de medida sino también las cúpulas giratorias en consonancia con la estandarización necesaria para las tareas asignadas. La participación del director del observatorio platense en la red coordinada por Mouchez volvía a definir, como en la observación del pasaje de Venus, el tipo de instrumental que se compraba con los recursos nacionales. Beuf pidió y obtuvo autorización del gobierno argentino para las compras; los instrumentos llegaron al país en 1890 y las actividades serían inspeccionadas periódicamente desde Francia (Rafinetti, 1904, p.10). A fines de ese año, el director esperaba poner a punto sus instrumentos para comenzar la tarea e integrarse a la investigación astronométrica internacional de confección de catálogos y mapas. (Figura 2).

Si la observación del pasaje de Venus había producido una diferencia clara de opiniones entre Beuf y Gould, esta nueva tarea de astronometría produciría un duro intercambio entre Mouchez y Thome, el nuevo director del observatorio cordobés. El primer debate estaba signado por diferencias en torno de cómo debían acumularse y organizarse los recursos de los observatorios y en esta segunda disputa se repite la temática, aunque a primera vista no lo parezca. Teniendo en cuenta la trayectoria del Observatorio de Córdoba en cuanto a la inserción de calidad en el trabajo astronómico internacional para la construcción de mapas y catálogos, algo que puede suscitar sorpresa es por qué el invitado al congreso astrofotográfico de París fue el director del recientemente puesto en funcionamiento observatorio platense. La primera invitación dirigida a Beuf estuvo orientada por una relación de trabajo ya construida entre los dos franceses: el director del observatorio platense y el del Observatorio de París. Como parte de esa trayectoria común, Mouchez y Beuf habían participado en la provincia de Buenos Aires orientando a las misiones extranjeras y a las locales para trabajar en la observación del tránsito de Venus; mientras que en Córdoba, el tránsito se observaba para 'salvar las apariencias'. Por otra parte, el vuelco de la porción mayoritaria de los recursos cordobeses a la elaboración de los catálogos australes por medio de la astronometría clásica germana habría dado cierta inflexibilidad a la posibilidad de reorientar esas tareas hacia las técnicas fotográficas de la Carte du Ciel. Afirmaba Thome en 1886, respecto de Mouchez y del proyecto de la Carte du Ciel:

\footnotetext{
Al Excmo. Señor Ministro de JusticiaDr. Eduardo Wilde... El diario 'La Nación' del 3 del corriente publica una carta del Almirante Mouchez al ... Ministro deO bras Públicas dela provincia de Buenos Aires y cuyo suelto le adjunto. Dicha carta, con el pretexto de ocuparse del Observatorio de 'La Plata', trata extensivamentey en términos completamente inadmisibles eintolerables del Observatorio Nacional. Consultado el Dr. Juarez Celman sobrela conveniencia deelevar a S.E. una relación de lo acontecido, mepermito incluirle la nota de protesta que le sometí y aprobó, rogando a S.E. tome las medidas del caso, si creequeel artículo referido puedehaber influido en laopinión pública respecto a nuestros trabajos.... (Thome, sept. 1886).
}

Así comenzaba el contraataque del director del observatorio cordobés a los dichos de Mouchez. No se encontró en los archivos la nota en cuestión, pero siguiendo la lectura de los copiadores se relevó otra carta en la que se volvía a argumentar más extensa y explícitamente respecto del disgusto con Mouchez. Aunque Thome defendía el método fotográfico para la astronomía, creía que en astronometría se obtendrían mejores resultados con el método por el que hasta ese momento se trabajaba en Córdoba para los catálogos. En esta nueva 


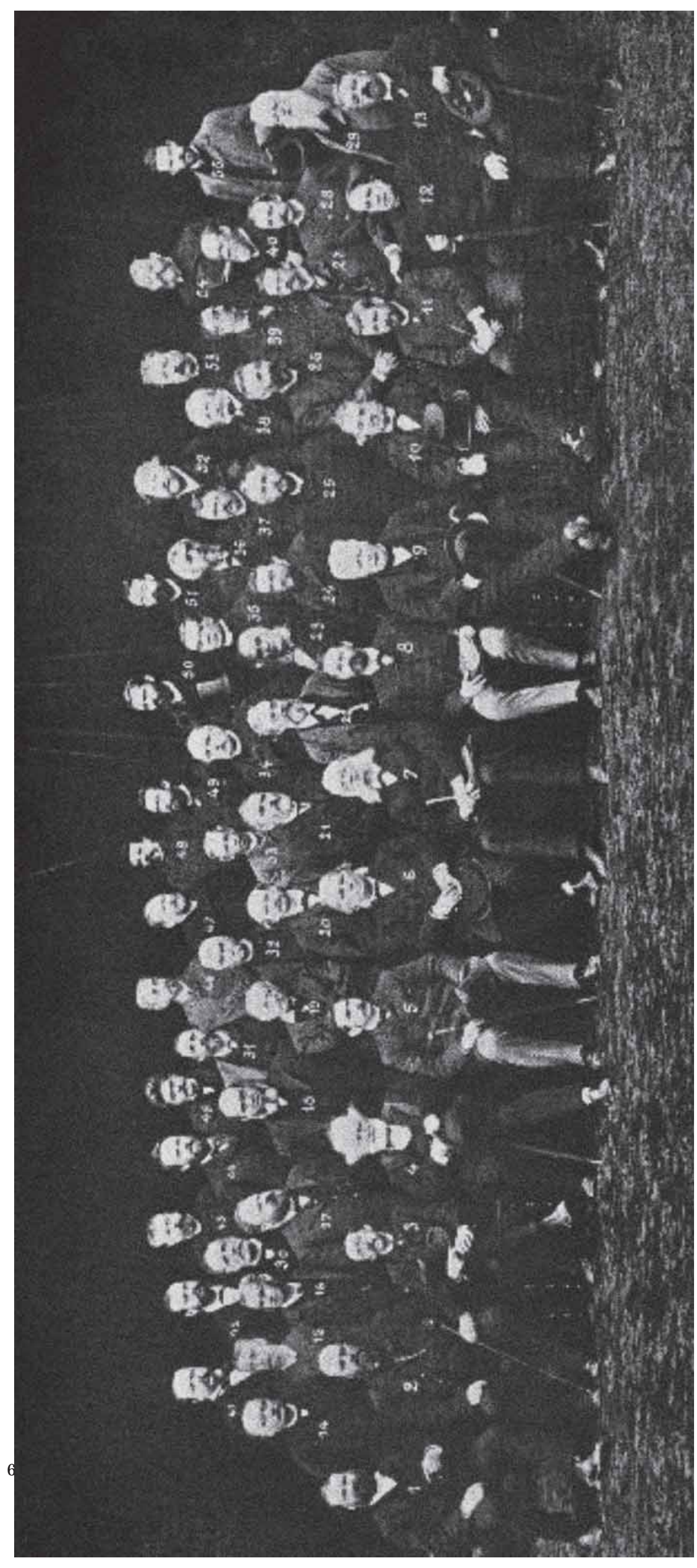

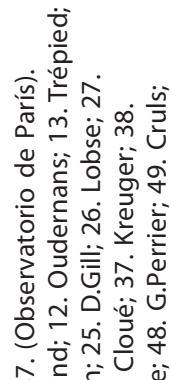

क्

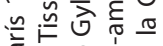
$\therefore=$ 요웡

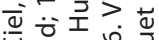
כ ฮั

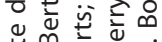
ฮㅇํㅇ f 뚜 훈 $\sigma$ 추

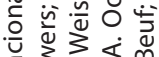
娄这 要 $\cong$ 过

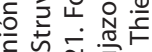
उ 0 更 管 हैं

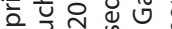
뜨을 屯 宊 흘

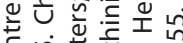

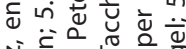
ป⿻一𠃋火 $\breve{c}$

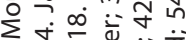

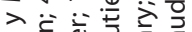
过艾券 응

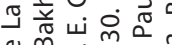

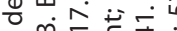
을

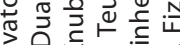

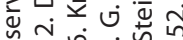

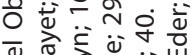

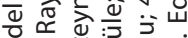

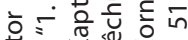
这范。

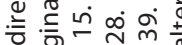

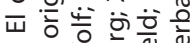
$\dot{\sim} \pi 3 \overline{0}$ 告 宁 
carta hacía explícita su opinión sobre Mouchez: no sería un "astrónomo notable" y habría escrito su carta "contra" el "Dr. Gould". En función de ello, Thome lo defiende:

\begin{abstract}
Está en la memoria y conocimiento detodos que el Dr. Gould hasido el egido miembro en todas las principales sociedades astronómicas y academias de ciencia de ambos continentes de Europa y de América, cabalmente después de haber dado a la ley los trabajos de este observatorio y a consecuencia de la feliz elección de los trabajos llevados a cabo. Esto es, pues, el veredicto solemne, imparcial y deliberado de aquellosque han logrado, por sus estudios y trabajos, posiciones eminentes de reputación universal en el mundo científico y astronómico, mientras quela carta del Sr. M ouchez encierra tan sólo la opinión privada; basada en el egoísmo y vanidad de un oficial de marina quien, ex oficio, ocupa una posición, distinguida ésta por la ilustración de los astrónomos que forman el personal del Observatorio. No temo ser tachado de parcialidad para con mi antiguo jefeal decir queera él, por su experiencia einteligencia, másapto queel al mirante Mouchez con sus arrogantes soi-disant para determinar, en 1870, la natural eza de los trabajos a emprender en Córdoba y que su palabra pesa, ante el mundo científico, infinitamente más que la de aquel señor (Thome, 16 sept. 1886).
\end{abstract}

Beuf, el director del Observatorio de La Plata, revestía exactamente esa característica de Mouchez que era atacada por Thome: oficial militar devenido en astrónomo. Thome defendía la trayectoria científica de "reputación universal", es decir, validada en el mundo de los científicos y no en el de los oficiales de Marina. Esta es la defensa del tipo de institucionalización de los observatorios germanos de mitad del siglo XIX con un fuerte núcleo en la investigación astronométrica administrada y ejecutada por constructores de catálogos. En cambio, en Francia, los observatorios se organizaban a través de la coordinación de re cursos materiales y humanos y estos últimos no sólo del medio científico astronómico, sino también pertenecientes a departamentos hidrográficos y navales. Entre los astrónomos de la Astronomische Gesellschaft, habían sido entrenados Gould y Thome, quien ahora se enfrentaba a la organización propuesta por el Observatorio de París a fines del siglo XIX que pretendía tender directos y amplios lazos con intereses de militares y civiles versados en técnicas geodésicas y cartográficas.

Antes de seguir con la carta de Thome se citará otra fuente que apoya la tesis de que la disputa era por la forma de organización de los recursos de los observatorios. En una carta enviada el 17 de diciembre de 1886, desde Córdoba, por Oscar Doering, el germano director de la Academia Nacional de Ciencias, a Florentino Ameghino, entonces director del Museo de La Plata, se hace visible el desacuerdo de Thome. Cabe aclarar que las malas opiniones de Doering sobre Beuf no pueden disociarse de su aspiración a dirigir el Observatorio o, cuando menos, su servicio meteorológico. Si bien debido a la negativa de Beuf a contratarlo se pueden encontrar extensos párrafos de Doering dedicados a la supuesta ineficiencia de Beuf, lo que aquí importa es que en una de estas cartas se hace mención directa al contraataque que estaba elaborando Thome:

Esimposiblereunir en un solo instituto 1) el Observatorio Astronómico, 2) el Observatorio y Oficina Central de M eteorología, 3) el Observatorio Magnético, 4) la Oficina Geodésica (buscando longitudes). Es un anacronismo que se ha salvado ya hacetiempo en todas partes del mundo y especialmenteen Francia. El Dr. Thome va a contestar así ... respecto delas opiniones vertidas sobre el Observatorio deCórdoba(Doering, 1886). 
Sin embargo, en Francia no sólo no parecía anacrónica la organización del instituto de La Plata, sino que, además, el director desu principal observatorio apoyaba decididamente los planes locales, postulándolos como integrantes de los de las naciones avanzadas. Como esto ya fue señalado, lo que interesa ahora es poner de relieve la supuesta réplica que elaboraría Thome, aunque éste ya había centrado la carta en otra línea, al decir que el problema con la dirección platense no se restringía a una disputa por la utilización de divergentes métodos científicos, sino que estaba ligada a diferentes criterios de centralización de recursos y organización de las tareas. Sin embargo, Thome (16 sept. 1886) transforma este desacuerdo en una discusión en lo concerniente al propio núcleo del método científico propuesto:

El método fotográfico queel al mirante Mouchez preconiza tanto fue practicado en este observatorio antes que se pensara hacerlo en París y antes que los hermanos Henry, val orando correctamentelosúltimos grandes adelantos del arte, enseñasen al almirante su aplicación. Por otra parte, la aserción que hace de que el Observatorio de La Plata 'podrá en una sola noche recoger la posición absolutamente exacta de un número de estrellas mucho mayor queel obtenido después de varios años detrabajos y con muchos gastos en el observatorio deCórdoba', no es verdad y aunque fuese, ten dría tanta utilidad práctica como la de un solo pozo de bal de en la irrigación de la zona recorrida por los canales de Córdoba.

Es interesante esta réplica que hace Thome respecto del aumento de productividad del trabajo astronómico que podría obtenerse por el método fotográfico, sobre todo teniendo en cuenta que el propio Gould era defensor de este método, aunque en su época todavía las técnicas tenían mucho para pulirse a fin de poder incorporarse a un trabajo sistemático. Sin embargo, Thome (16 sept. 1886) insistía en que el fondo de la disputa era metodológico:

Respecto alos trabajos en curso deejecución en este Observatorio, debo manifestar que severifican según el programa original establecido, encaminados hacia idéntico fin queel mismo Sr. M ouchez se propone alcanzar por otros métodos: y me es grato aclarar que ellos adelantan con la rapidez permitida por las circunstancias, y esto, con tanto y más éxito como podría hacerlo este señor Al miranteen las mismas condiciones. Dejamos así salvada la dignidad y reputación del establecimiento que dirijo ...

Así, Thome inicialmente defiende la no utilización de la fotografía en la construcción de catálogos y mapas y la continuidad con los métodos de trabajo visuales ya usados por Gould lo cual era, antes que nada, una defensa de una forma de empleo de los recursos tal como se estaba practicando. De lo contrario, Thome tendría que admitir que su trabajo para la Durchmusterug era parte de esos "varios años de trabajo y con muchos gastos" que el Observatorio de La Plata podía realizar con menos gastos en una sola noche, según la visión de Mouchez, y aquí se percibela inercia quelos recursos materiales, losentrenamientos ya recibidos y los planes ya trazados imponen en las instituciones. El maestro de Thome, aunque entrenado y formado en el terreno de la astronometría clásica visual, sí había atendido y divulgado las ventajas del método fotográfico. En 1882, decía Gould respecto de los nuevos métodos fotográficos:

heexpuesto exten samente el carácter y objetos de estenuevo método de observación, el quepermitequese consigan dentro de un corto intervalo representaciones delasposiciones 
relativas de una gran cantidad de objetos. Estos pueden medirse en cualquier fecha posterior y conservarse permanentemente para comprobar la exactitud delas mediciones verificadas o repetirlas indefinidamente. Así, pueden conseguirseen una sola nochelos datos que de otra manera apenas se conseguirían en un año; efectuándose la obra de observación instrumental en los tiempos, las circunstancias y condiciones cómodas. El Observatorio Argentino es el único que hasta la fecha ha al canzado a llevar a cabo este sistema de observaciones. Ya tenemos en nuestro poder una serie bastante extensa de impresiones de estrellas para las cuales abrigo sospechas de una paralaje mensurable (Gould, mayo 1882; cursivas añadidas).

Son casi las mismas palabras de Mouchez, pero enunciadas un tiempo antes por Gould. Efectivamente, el anterior director del Observatorio de Córdoba había vislumbrado la perspectiva que ahora parecía estar encarnándose en los planes de Mouchez para el Observatorio de La Plata. Para Gould, los inconvenientes en la utilización de esa técnica tenían que ver, por un lado, con un insuficiente desarrollo de los aparatos de relojería necesarios para que los tel escopios pudiesen seguir el objeto a fotografiar y, por el otro, con la barrera que el prolongado tiempo de exposición de las placas todavía requería. Sin embargo, suponía que en breve los problemas serían superados:

como todo lo que en este mundo vale algo, no se consigue sin grandes dificultades y gravísi mos obstácul os. ... No obstante. ... todos los cuidados y expedientes más sutiles, parece al gunas veces casi imposi ble conseguir la uniformidad absoluta. ... influencias desconocidassecombinan para estorbar el movimiento regular del aparato de relojería.... Los grandes adel antos recientes. ... Las llamadas 'planchas instantáneas secas'. ... permiten ahora una gran abreviación del tiempo de exposición. ... hemos llegado a fotografiar estrellas que seguramente no al canzan la undécima magnitud. ... (Gould, mayo 1882).

Gould reivindicaba para el observatorio cordobés el hecho de haber dado un paso importante al avanzar en trabajos astronométricos con la incorporación de la técnica fotográfica. Si hablaba así por haber conseguido captar estrellas de la 11ª magnitud, es difícil asimilar su opinión a la que emitiría su discípulo Thome respecto de las tareas que proponía Mouchez, quien contaba con la posibilidad de llegar hasta estrellas de la 14a magnitud y con aparatos de relojería adecuados para las exposiciones de las placas. Otra vez están en cuestión formas de administración de los recursos humanos y materiales disponibles, aunque los discursos cobren formas de discusiones sobre métodos y objetivos científicos.

\section{Conclusiones}

Las dudas respecto de la utilidad científica de la observación del pasaje de Venus señaladas por Gould desde Córdoba se correspondían con un estadio del debate que sostenían los constructores de catálogos celestes en el plano internacional. Sin embargo, el impulso dado a la tarea por parte de los miembros del Bureau des Longitudes, de Beuf y del gobierno de la provincia de Buenos Aires ponía de manifiesto que la propia participación en la tarea era una de las formas de la competencia internacional por la acumulación de recursos en los observatorios. Con la misión se proponía una línea de trabajo que incluía la posibilidad 
de coordinar recursos ingenieriles, militares y navales para la realización de tareas astronométricas, cartográficas, hidrográficas y geodésicas y ésta fue la alternativa que cristalizó en el Observatorio de La Plata.

Las disyuntivas en estas discusiones estaban marcadas por las redes de trabajo que construían los directores de los principales observatorios involucrados en la competencia internacional y son estas redes las que se ocultan entre los debates científico-metodológicos de los directores de los observatorios locales sobre el pasaje de Venus o sobre la Carte du Ciel. El entramado de las tareas Ilevadas a cabo por técnicos locales, por el director del Observatorio de La Plata, por el del Observatorio de París y por los miembros del Bureau des Longitudes explica muchas de las características de la organización del observatorio platense. Lejos de mostrar que la producción del Observatorio fue nula, la red confirma que el director del observatorio platense logró que éste produjese conforme lo requerían instituciones que preponderaban en los debates sobre convenciones espacio-temporales en la época.

Cabe aclarar que en un período que aquí no se analiza, la organización del trabajo del observatorio platense, que había promovido el Bureau des Longitudes y cuyo eje era la vinculación con otras reparticiones estatales, se impondría como meta para todos los observatorios argentinos financiados por el Estado. En la década que se inicia en 1930, quedarían en el camino los intentos de los directores del Observatorio de Córdoba que buscaban asegurar un trabajo de nivel en la construcción de catálogos mediante entrenamiento intensivo de astrónomos extranjeros en detrimento de planes de trabajo más ligados a la enseñanza local o al fomento de las alianzas de trabajo en el seno del Observatorio entre los astrónomos y otros técnicos o profesionales, ya fuesen ingenieros, topógrafos, agrimensores, figuras militares o del gobierno. Estas y otras cuestiones serían imposibles de desentrañar observado el tema bajo el sesgo que les han dado los primeros directores del observatorio cordobés o bien la historiografía tradicional de las ciencias a la fundación del observatorio platense.

\section{NOTAS}

${ }^{1}$ El trabajo de la astronomía en el siglo XIX, como en épocas anteriores, servía a la cartografía y a la navegación; pero, en correlación con la densidad que adquiría la trama del comercio mundial y el tránsito de personas en ese siglo se intentaban unificar catálogos y mapas celestes que antes circulaban en zonas más restringidas. Algunos astrónomos germanos encabezaban dicha iniciativa que requería que algunos observatorios se ubicaran en tierras australes, desde donde el 'cielo del sur' podía ser observado (Hodge, 1971).

${ }^{2}$ La interposición de Venus entrela Tierra y el Sol se había observado, con una frecuencia menor a una vez por siglo, en dos eventos separados cada ocho años. Desde el siglo XVIII, se coordinaban misiones desde diferentes puntos de nuestro planeta para usar el Sol como fondo contra el que medir la paralaje de Venus, de la que se calculaba la solar, para así poder deducir la distancia entre la Tierra y el Sol y, en consecuencia, la escala de nuestro sistema planetario. La gran distancia que nos separa del Sol, así como la brumosa e indefinida natural eza de su disco, hacía imposible medir la paralaje solar de manera directa (Orchiston, Dick, Love, 1998).

${ }^{3}$ Paradójicamente, en la conferencia de Washington, al gunos de los contendientes argumentaban que las únicas neutrales eran las estrellas, haciendo alusión a que sólo las coordenadas estelares permitían una referencia espacial que no pasaba por una nación. En todo caso, los mapas celestes eran condición para cartografiar en mar y tierra, mover ejércitos, hombres y mercancías. La hora fijada por los astrónomos era 
una variable interdependiente con la longitud terrestre y la casi simultaneidad de la telegrafía permitía establecer diferencias horarias para construir los mapas nacionales y mundiales (Galison, 2003).

${ }^{4}$ Gould jugaría un papel importante, a su regreso a los Estados Unidos, en las expediciones de navegación que bregaban por el establecimiento de las longitudes mundiales (Galison, 2003).

${ }^{5}$ En Estados Unidos, el Congreso destinó un monto de 75 mil dólares para la misión, más diez mil dóláres para poner a punto los instrumentos. Simon Newcomb era uno de los astrónomos que estaba en una de Ias misiones, en la del Cabo de Buena Esperanza, pese a sus dudas respecto de los resultados (Warner, 1971; Orchiston, Dick, Love, 1998; Lankford, 1987).

6 "Je vous dédie cet ouvrage comme un hommage de ma vive reconnaissance pour les nombreuses marques d'estime dont vous n'avez cessé de m'honorer. Je l'ai écrit dans un pays qui a été le théatre de l'un de vos plus importants travaux hydrographiques, et pour lequel vous avez conservé la sympathie la plus sincère. Vous lui en donnez constamment des preuves en mettant à son service votre haute expérience et votre zêle infatigable pour tout ce qui concerne le progrès de la Science: je suis heureux de l'occasion qui m'est offerte d'en pouvoir témoigner publiquement. Je suis avec profond respect, Amiral, Votre très reconnaissant. F. Beuf". Todas las traducciones desde el francés son libres y propias.

7 Para cifras concernientes a la extensión de las vías férreas en el período se pueden consultar tanto trabajos clásicos como actuales: Colin, 1983; López, 1994; Regalsky, 1989; Roccatagliata, 1987; Salerno, 2008; Scalabrini Ortiz, 1986; Wright, 1980. También se encuentran respecto de la extensión de comunicaciones y telégrafos: Bose, 1966; Cárcano, 1893; Carles, 1898; Castro Esteves, 1934; Schäffner, 2008.

${ }^{8}$ Esto además ya lo mencionaba Mouchez desde 1882, cuando le habían Ilegado comentarios de la intención de Dardo Rocha y ponía a disposición toda la ayuda de los recursos franceses del Bureau des Longitudes (Mouchez, 1882).

9 “hordes d'Indiens qui I'occupaient à l'état sauvage."

10 "naturellement pacifique et civilisateur."

11 "nations avancées."

12 "L'Annuaire que M. Beuf, directeur du nouvel observatoire de La Plata vient de publier sera certainement accueilli avec faveur. M. Beuf a voulu prendre comme modèle l'Annuaire de Bureau des Longitudes, en le réduisant un peu. 160 pages sont consacrées aux données astronomiques proprement dites; le reste du volume (260 pages) est ocupé par les poids et mesures métriques et leur comparaison avec les mesures anciennes des différentes provinces, par la statistique, la géographie et la météorologie."

13 “1. M. Mouchez. Création d'un observatoire d'étude dans le parc Montsouris, par le Bureau des Longitudes. / 2. M. Faye. Les orages et sur la formation dela grêle. Théories, enquêtes et vérifications. / 3. Eléments astronomiques les plus usuels tirés de la Connaissance des temps. / 4. Articles et tables de statistique. / 5. Saisons, Calendriers julien, Grégorien, Républicain, israélite, musulman. Levers, couchers et passages au Méridien du Soleil, de la Lune, et des Planètes, phénomènes astronomiques, durée des jours, aspect des Planètes, éclipses, position des étoiles, temps sidéral, éphémérides. Calcul des marées : heures de pleine mer à Brest et plusieurs grands ports d'Europe. / 6. Tableaux des principaux éléments du système solaire, Planètes téléscopiques entre Mars et Jupiter. / 7. Poids et mesures en France, conversions entre les différentes unités de mesure, mesures des pays étrangers. / 8. Monnaies: monnaies française, fabrication des monnaies, tableaux par nature de pièces, tableaux d'amortissements et d'intérêts. / 9. Statistique: populations de Paris et de la France, superficie mouvements de la population, mortalité, consommation. / 10. Position des coordonnées géographiques des différents points du globe, tableau des hauteurs des principales montagnes du monde. / 11. Diverses tables de physique, et de thermochimie. / 12. Planches ( 4 en double page et 2 dépliantes): Vue de l'Observatoire de la Marine, dans le parc de Montsouris. Carte des lignes d'égale déclinaison magnétique en France en 1875. Une planche en double page du revolver photographique de Janssen (intérieur). Carte des lignes d'égale déclinaison magnétique en France en 1876. Carte des parties de la France et des Pays-Bas ravagées par l'orage le 13 juillet 1788. Carte générale de l'orage du 13 juillet 1788."

\section{REFERENCIAS}

BABINI, José

Historia de la ciencia en la Argentina. Buenos Aires: Solar. 1986.
BABINI, José

La evolución del pensamiento científico en la

Argentina. Buenos Aires: Fragua. 1954. 
BERNAOLA, Omar.

Enrique Gaviola y el Observatorio Astronómico de Córdoba: su impacto en el desarrollo de la ciencia argentina. Buenos Aires: Saber y Tiempo. 2001.

BEUF, Francis.

Curso de geodesia y topografía. Buenos Aires: Imprenta Europea. 1886.

BEUF, Francis; PERRIN, Edouard.

Considérations nouvelles sur l'observation et la réduction des distances lunaires en mer. Comptes Rendus Hebdomadaires des Séances de I'Académie des Sciences, Paris, t.86, p.758-761. 1878.

BOISTEL, Guy.

Instruire les marins avec les moyens du bord: Observatoire de Montsouris. Les Genies de la Science, Paris, n.28, p.29-35. 2006.

BOSE, Walter.

Historia de las comunicaciones en la República Argentina (Antecedentes y período 1862-1930). In: Academia Nacional de la Historia. Historia argentina contemporánea. v.2, sección 2. Buenos Aires: El Ateneo. p.160-212. 1996.

BUREAU DES LONGITUDES.

Annuaire pour les annes 1876 et 1877. París: Gauthier-Villars. 1877.

CÁRCANO, Ramón.

Historia de los medios de comunicación y transportes en la Argentina. Buenos Aires: Lajouane. 1893.

CARLES, Carlos.

Legislación y tarifas: telégrafos nacionales. Buenos Aires: Compañía Sud-Americana de Billetes de Banco; Dirección General de Correos y Telégrafos. 1898.

CARRASCO, Gabriel.

La unidad horaria de la República Argentina.

Santa Fe: Ministerio de Agricultura de la Provincia de Santa Fe. 1893.

CASTRO ESTEVES, Ramon de.

Historia de correos y telégrafos de la República Argentina. Buenos Aires: Ed. Oficial de la Dirección General de Correos y Telégrafos. 1934.

CHAUDET, Enrique.

La evolución de la astronomía en la República Argentina durante los últimos cincuenta años (1872-1922). Buenos Aires: Sociedad Científica Argentina. (Evolución de las Ciencias en la República Argentina, V). 1926.

COLIN, Lewis.

British Railways in Argentina, 1857-1914: a case study of foreing investment. London: Institute of Latin American Studies/University of London. 1983.

DOERING, Oscar.

Carta a Ameghino. In: Ameghino, Florentino. Cartas. OC y CC Florentino Ameghino XXI. Documentos compilados por A. Torcelli A. en 1930. La Plata: Taller Ed. Oficiales. p.273-409. 1886.

GALISON, Peter.

Relojes de Einstein, mapas de Poincaré: los imperios del tiempo. Barcelona: Crítica. 2003.

GERSHÁNIK, Simón.

El Observatorio Astronómico de La Plata en el octogésimo aniversario de su fundación. La Plata: Publicación del Observatorio. 1966.

GONZÁLEZ GONZÁLEZ, Francisco.

La carta fotográfica del cielo en España. Llull: Revista de la Sociedad Española de la Historia de las Ciencias y de las Técnicas, Madrid, v.12, n.23, p.323-340. 1989.

GOULD, Benjamin.

Informe. Córdoba. Archivo del Museo

Astronómico de la Universidad Nacional de

Córdoba, série Copiador 20 de mayo de 1878 a

16 de agosto de 1888 (Observatorio

Astronómico de Córdoba). nov. 1882.

GOULD, Benjamin.

Informe del año 1881 al ministro de JCIP, Dr.

Eduardo Wilde. Córdoba. Archivo del Museo

Astronómico de la Universidad Nacional de

Córdoba, série Copiador 20 de mayo de 1878 a

16 de agosto de 1888 (Observatorio

Astronómico de Córdoba). mayo 1882.

HODGE, John.

Benjamin Aptthorp Gould and the founding of the Argentine National Observatory.

The Americas, New York, v.28, n.2, p.152-175. 1971.

LANKFORD, John.

Photography and the 19th-century transits of Venus. Technology and Culture, Baltimore, n.28, p.648-657. 1987.

LE NOUVEL OBSERVATOIRE...

Le nouvel observatoire astronomique de La Plata. Bulletin Astronomique, Paris, serie I, v.1, p.63-64. 1884

\section{LOIS, Carla}

La invención de la tradición cartográfica argentina. Revista Litorales, Buenos Aires, v.4, n.4. Disponible en: http://litorales.filo.uba.ar/ web-litorales5/articulo-1.htm. 2004.

LÓPEZ, Maria.

Historia de los ferrocarriles nacionales. Buenos Aires: Lumière. 1994. 
MOUCHEZ, Amédée.

Le nouvel observatoire astronomique de La Plata. Bulletin Astronomique, Paris, serie I, v.3, p.417-421. 1886.

MOUCHEZ, Amédéé.

Observation du passage de Vénus dans la République Argentine. Comptes Rendus Hebdomadaires des Séances de I'Académie des Sciences, Paris, n.95, p.1182-1184. 1882.

ORCHISTON, Wayne; DICK, Steven; LOVE, Tom.

Simon Newcomb, William Harkness and the nineteenth-century American transit of Venus expeditions. Journal for the History of Astronomy, New York, v.29, n.96, p.221-257. 1998.

PERRIN, Edouard.

Observation du passage de Vénus, faite à Bragado (République Argentine). Comptes Rendus Hebdomadaires des Séances de l'Académie des Sciences, Paris, n.97, p.227-229. 1883.

RAFINETTI, Virgilio.

Descripción de los instrumentos astronómicos del Observatorio de La Plata. La Plata: Talleres de Publicaciones del Museo de La Plata. 1904.

REGALSKY, Andrés.

Foreign capital, local interests and railway development in Argentina: French investments in railways, 1900-1914. Journal of Latin American Studies, London, v.21, n.3, p.425-452. 1989.

REVUE DES PUBLICATIONS...

Revue des Publications Astronomiques: Anuario del Observatorio de La Plata para el año 1887. Bulletin Astronomique, Paris, serie I, v.4, p.291-291. 1887.

REYES, Iván.

La Cape Photographic Durchmustrerung. Revista Astronómica, Buenos Aires, v.4, n.6, p.339-345. 1932.

RIEZNIK, Marina.

Historia de la astronomía en la Argentina: Ios observatorios de Córdoba y de La Plata (18711935). Tesis (Doctorado) - Facultad de Filosofia y Letras, Universidad de Buenos Aires, Buenos Aires. 2008.

ROCCATAGLIATA, Juan. Los ferrocarriles en la Argentina: un enfoque geográfico. Buenos Aires: EUdeBA. 1987.
ROCHA, Dardo.

Carta al presidente de la comisión internacional que se ocupara del fenómeno, 8 de enero de 1883. 1883. In: Sociedad Científica Argentina. La evolución de las ciencias en la República Argentina. t.7: Astronomía. Buenos Aires: Sociedad Científica Argentina. p.9. 1979.

SALERNO, Elena.

Los ferrocarriles del Estado en Argentina y su contribución a la ciencia. História, Ciências, Saúde - Manguinhos. Rio de Janeiro, v.15, n.3, p.657-678. 2008.

SCA.

Sociedad Científica Argentina. La evolución de Ias ciencias en la República Argentina. t.7: Astronomía. Buenos Aires: Sociedad Científica Argentina. 1979.

SCALABRINI ORTIZ, Raúl.

Historia de los ferrocarriles argentinos. 9.ed.

Buenos Aires: Plus UItra. 1.ed., 1948. 1986

SCHÄFFNER, Wolfgang.

Los medios de comunicación y la construcción del territorio en América Latina. História,

Ciências, Saúde - Manguinhos, Rio de Janeiro, v.15, n.3, p.811-826. 2008.

THOME, John.

Observatorio Nacional Argentino de Córdoba. Buenos Aires: Imprenta Coni Hermanos. 1906.

THOME, John.

Carta a Wilde. Córdoba. Archivo del Museo

Astronómico de la Universidad Nacional de Córdoba, série Copiador 20 de mayo de 1878 a

16 de agosto de 1888 (Observatorio

Astronómico de Córdoba). 16 sept. 1886.

THOME, John.

Carta a Wilde. Córdoba. Archivo del Museo Astronómico de la Universidad Nacional de Córdoba, série Copiador 20 de mayo de 1878 a 16 de agosto de 1888 (Observatorio Astronómico de Córdoba) [fecha borrada, entre 11 y 15 sept. 1886]. sept. 1886.

WARNER, Deborah.

Lewis Rutherfurd: Pioneer astronomical photographer and spectroscopist. Technology and Culture, Baltimore, n.12, p.190-216. 1971.

WRIGHT, Winthrop.

Los ferrocarriles ingleses en la Argentina: su influencia en el nacionalismo económico, 1854-1948. Buenos Aires: Emecé. 1980.

\section{uuuUUU}

